\title{
Innovation opportunities focusing design for sustainability: an ecodesign strategy wheel application
}

\author{
Anderson Gomes Ferreira ${ }^{a}$ Bárbara Rangel de Carvalho Braga de Mendonça ${ }^{b}$, Dimitri Bassani Santos Neves", \\ Rafael Mizerani Couto Moreirab, Eduardo Romeiro Filhoc \\ -Departamento de Engenharia Mecânica, Universidade Federal de Minas Gerais - UFMG \\ bEscola de Design, Universidade Estadual de Minas Gerais - UEMG \\ Departamento de Engenharia de Producão, Universidade Federal de Minas Gerais - UFMG \\ e-mails: anderson.goferreira@gmail.com; barbarademendonca@gmail.com; dimitribsn@gmail.com; mizeranimoreira@gmail.com; romeiro@dep.ufmg.br
}

\begin{abstract}
The use of laptops computers is increasing and this model surpassed the desktop computer as the most popular of the personal computer market. On the extended use situations, the laptop can causes ergonomic issues, and the use of an adjustable table is demanded to raise the screen to the user eye-line height in order to alleviate this problem. The manufacturing of the laptop stand causes environmental impact, still requiring the production of other complementary peripherals for the stand to be effective. this paper describes a simplified LCA - Life Cycle Assessment linked to an ESW - Ecodesign Strategy Wheel method application highlighted a great opportunity of innovation during the evaluation of the manufacturing process of the UpTable portable laptop stand, providing solutions for both the ergonomic issue and the environmental sustainability. Proposed manufacturing process eliminates the peripherals redundancy and promotes economy of supplies with no prejudice to the portability that characterizes the device, reducing the environmental impact during the manufacturing process, utilization and discharge of the product.
\end{abstract}

Keywords: laptop stand, life cycle analysis, sustainability and innovation, Green manufacturing.

\section{Introduction}

The versatility of portable computers led notebooks to assume the position of study and work stations, replacing the desktop as the main or single computer. The use of laptops has spread rapidly in recent years while still causing ergonomic hazard to the users (FRANZ; GUIMARÃES; AREZES, 2011). It's important to use a laptop stand, in order to avoid this problem due to its capability of promoting the use of the device in ergonomically healthy positions. According to a research evaluating different body postures during the use of various laptop stands, the best alternative is the one that elevates the screen and demands less bending of the neck while adding extra keyboard and mouse (ASUNDI et al., 2012), as shown in Figure 1 bellow.

Starting from this situation and considering the increase of laptop support use, this paper aims at identifying and evaluating the life cycle of the laptop stand, regarding the environmental impacts of its manufacturing process, demonstrating the value of LCA and ESW as a contribution to product redesign and improvement. The article also proposes innovation in the process by analysing and applying manufacturing engineering and design knowledge (the relationship between industrial design and innovation is approached by Pereira and Naveiro (2007) and, resulting in a contribution to innovation, considered as a basic element for sustainable growth in the long term for organizations (BAGNO; LEIVA; OLIVEIRA, 2016).

\section{Method}

The conducted research is exploratory of the life cycle of the UpTable adjustable laptop stand, including elements of a simplified LCA - Life Cycle Assessment and the ESW - Ecodesign Strategy Wheel. This product has been chosen due to its popularity in Brazil. Table 1 below presents the main aspects of the product.

Figure 2a presents the product ad, featuring sale price of $R \$ 39,90$ (shipping not included). Figure $2 b$ presents usage suggestion according to the manufacturer (ASYS - PODUCTS, 2016).

The first stage of the research consisted of a study based on non-participant elements, including manufacturer data collection via electronic mail, application of mixed sampling techniques alongside end-users from both enterprise and 

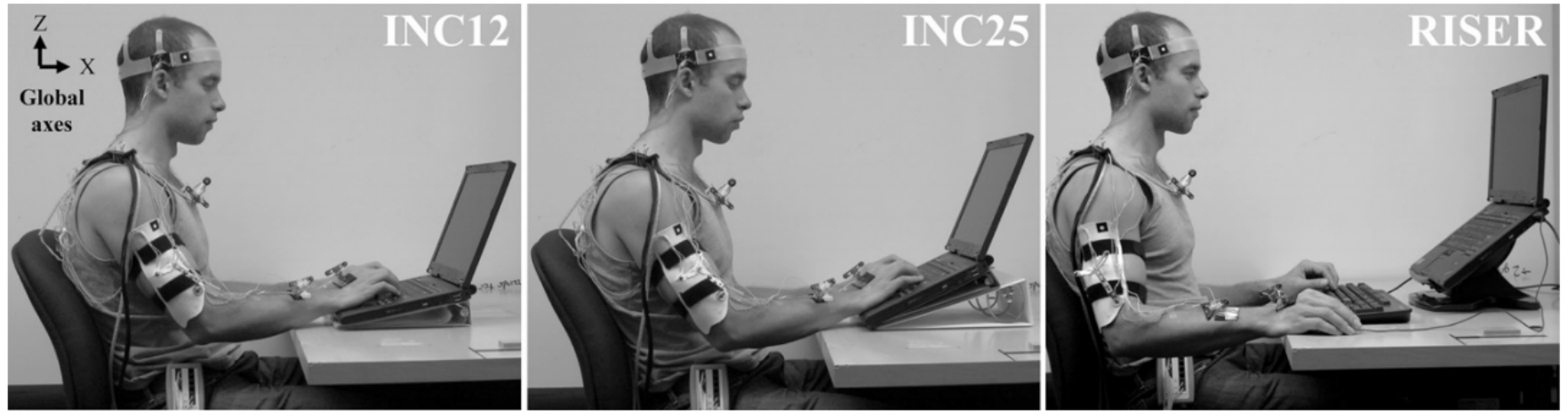

Figure 1. Pictures of laptop user in three different positions: $12^{\circ}$ inclination (INC12), $25^{\circ}$ inclination (INC25) and on screen elevating stand connected to mouse and external keyboard operated on the height of the table (RISER). Source: Asundi et al. (2012).
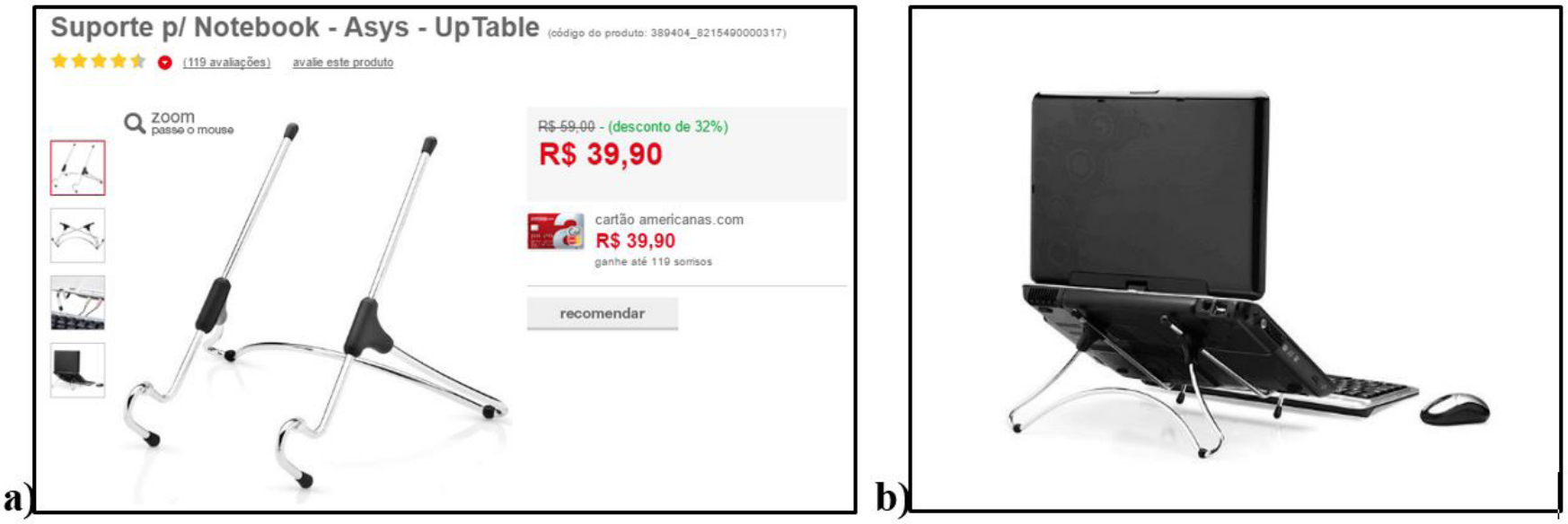

Figure 2. (a) Product ad from Americanas online shop (LOJAS AMERICANAS, 2016). (b) Laptop stand picture (ASYS PRODUCTS, 2016).

Table 1. UpTable adjustable laptop stand.

\begin{tabular}{|l|l|}
\hline \multicolumn{1}{|c|}{ ITEM } & \multicolumn{1}{c|}{ DESCRIPTION } \\
\hline Trade name & Asys UpTable adjustable laptop stand \\
\hline Manufacturer & Azevedo de Assis e Cia. Ltda (trade name: Asys Conceitos Inovadores) \\
\hline Package dimensions & $32 \times 22 \times 3 \mathrm{~cm}$ \\
\hline Folded product dimensions & $26 \times 16 \times 2 \mathrm{~cm}$ \\
\hline Net weight (kg) & 0.290 \\
\hline Gross weight approx. & $0.345 \mathrm{Kg}$ \\
\hline Materials & $\begin{array}{l}\text { Structure in bending chrome steel profile, plastic connectors and caps in the contact points with the } \\
\text { notebook and table }\end{array}$ \\
\hline
\end{tabular}

Source: Asys - Products (2016).

personal environments, and general manufacturing process analysis, with estimation of the data the manufacturer did not provide. Second stage consisted of applying principles of four different sustainability design tools (van HEMEL, 1998), included in: ESW - Ecodesign Strategy Wheel (ALVES et al., 2016, van HEMEL; CRAMER, 2002);
LCA - Life Cycle Assessment (NIGRI et al., 2014); MET - Material, Energy and Toxicity Matrix and VL - Verification List (FRAZÃO et al., 2003). Based on the tools application findings, a new design concept was proposed to the manufacture of a notebook containing a built-in adjustable stand. 


\section{LCA - Life Cycle Assessment}

The LCA tool aims at the comprehension of the existing impacts along the product life cycle, including manufacturing and use. This tool allows the evaluation of environmental aspects and impacts of a product by means of inventory of environmentally relevant inputs and outputs of the product system in accordance to ISO 14040 (ASSOCIAÇ ̃̃O..., 2009a, b). LCA is a dynamic and iterative process with three moments: Scope Delimitation, Inventory Analysis, and Impact Assessment.

\subsection{LCA Scope Delimitation}

Survey covered the analysis scope from the manufacturing plant gates, including raw-materials receiving, to the disposal of the product by the end-user. Therefore the analysis system includes the four following processes: Raw Material Transportation; Manufacturing, Packaging and Distribution; Use and Disposal. These processes present inputs and outputs as shown in the process flowchart in Figure 3.

\subsection{Inventory analysis}

Inputs and outputs were identified and broken down into stages.

\subsubsection{Process 1: Raw Material Transportation}

The Raw Material Transportation process can be defined by three stages as shown on Figure 4.

The process Raw Material Transportation takes place using motor vehicles that work with fossil fuel that emits particles such as gases, steam, acid mist and SO2 to the atmosphere. This procedure may also generate automobile external noise. The raw material consumed in the manufacturing process, steel profile and polymer parts, enters the system through this process.

\subsubsection{Process 2: Manufacturing}

Manufacturing process comprehends four operations, as presented on Figure 5.

First operation is the steel profile cutting that uses an automatic guillotine. Pieces of two different lengths are

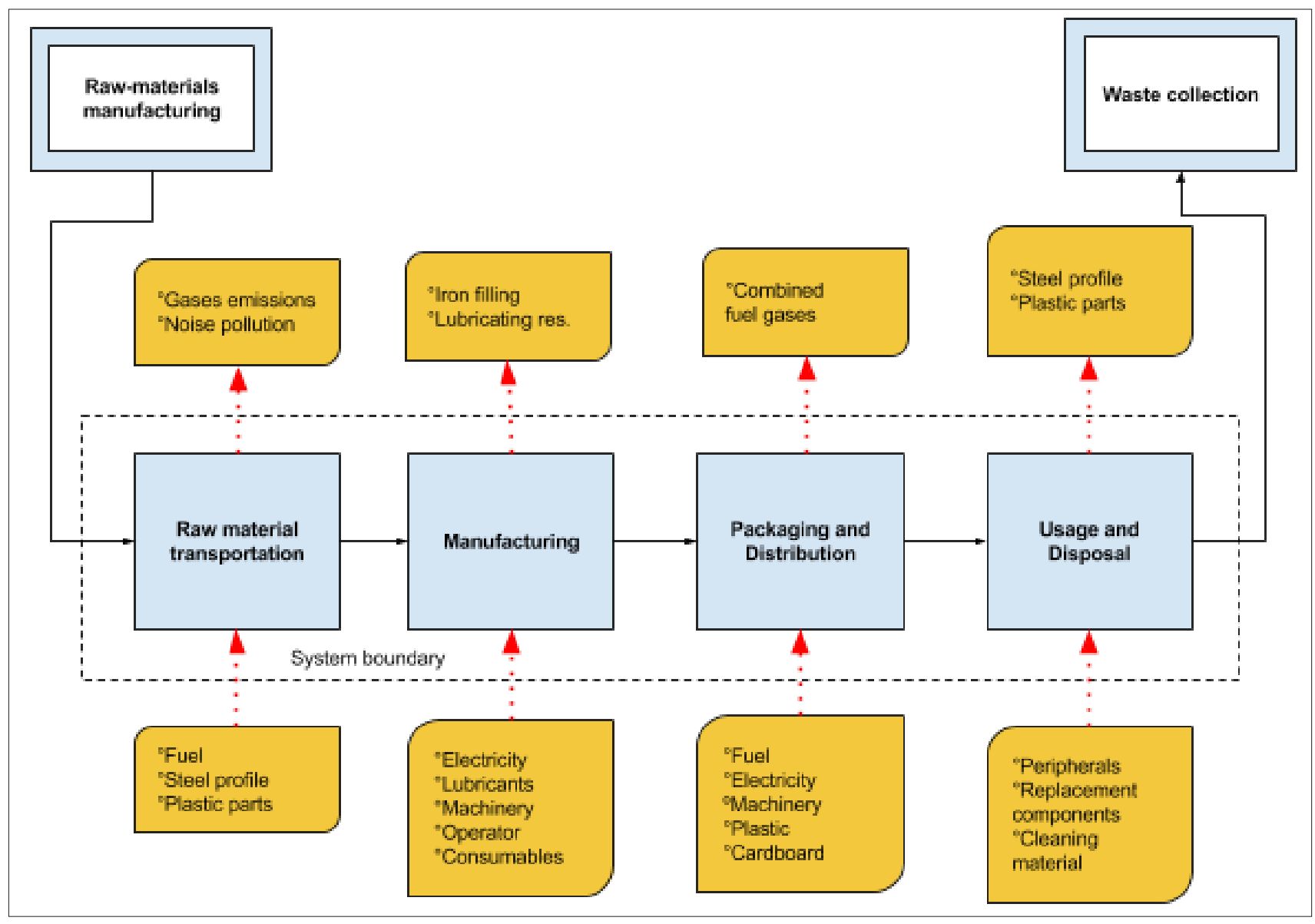

Figure 3. Product life cycle scope of the UpTable laptop stand. 


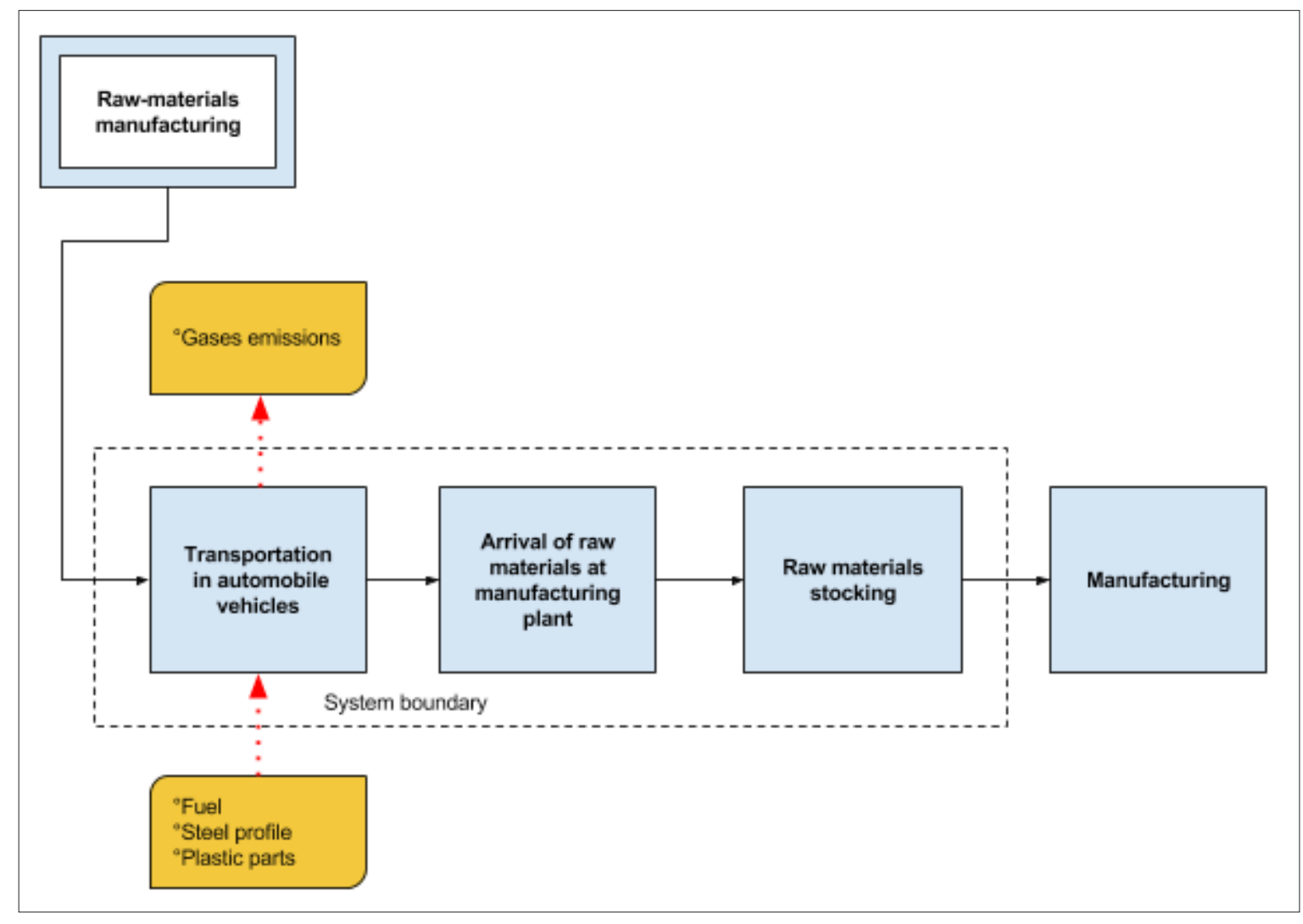

Figure 4. Flowchart of Raw Material Transportation process.

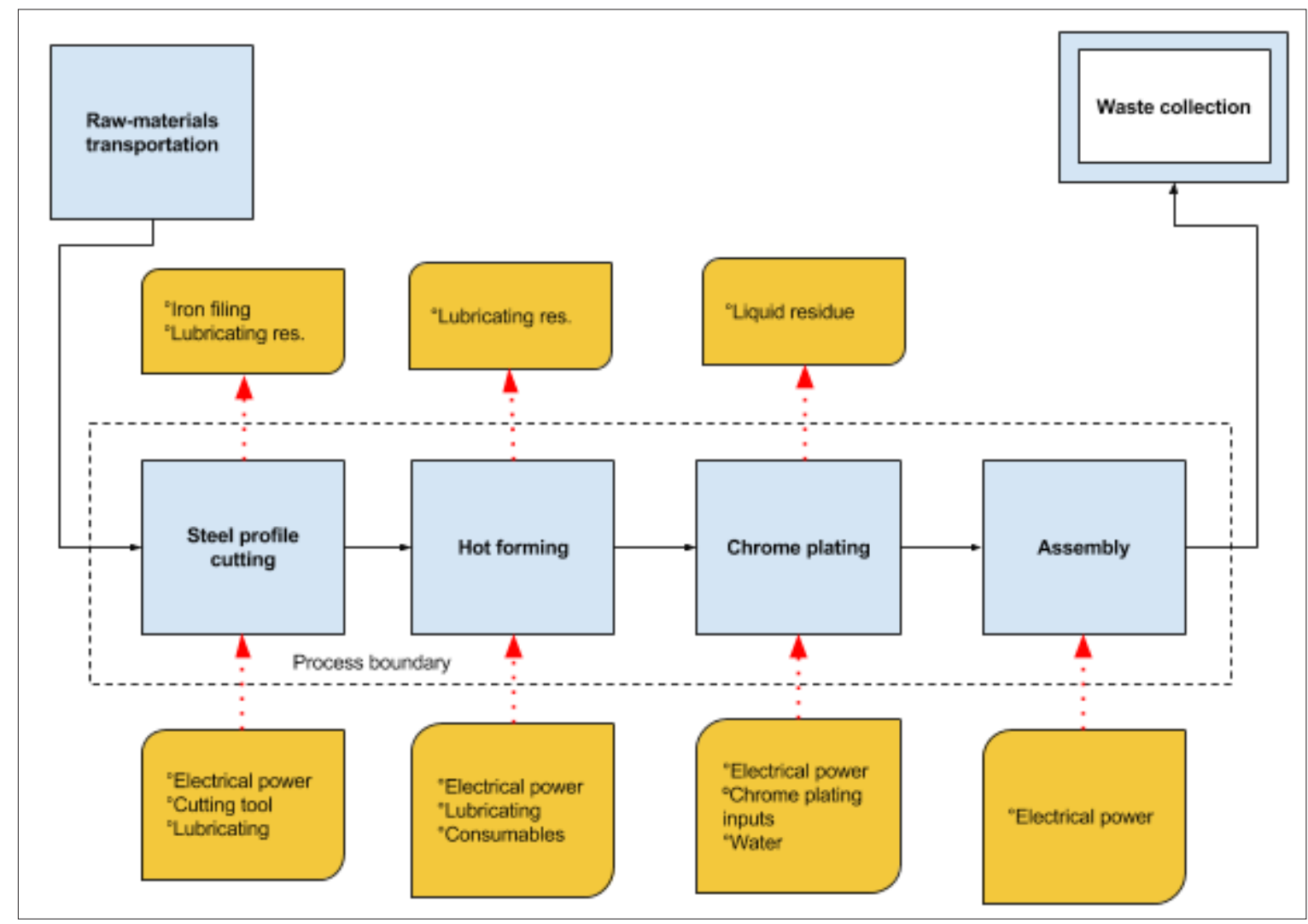

Figure 5. Flowchart of Manufacturing process. 
produced, the longer one that will stay in contact with the table, and two smaller parts of same length that will be in contact with both the laptop and the table surface. Second operation is the steel profile folding, to shape the three metal parts that compose the product, which is done using an automatic folding machine. Third operation is the chromium plating process of the metallic parts that form the product, made to avoid oxidation due to atmospheric humidity exposition. On the environmental regard, the use of chromium should be avoided due to its high toxicity potential levels that lead to major soil pollution (SILVA; PEDROZO, 2001, PEDROTTI; MISTURA, 2010). Fourth operation is the assembly, when plastic endings and joints are used to connect the metallic structures and finishing the product. Notice that the four operations, added the material transposition between the machines, is conducted using electric power.

\subsubsection{Process 3: Packaging and Distribution}

The Packaging and Distribution process consists of four steps, as shown on Figure 6. The primary packaging is produced in printed finish in $4 \times 0$ couché cardboard.
The packaged unit is assembled into groups that will be repackaged in a larger carton also. In turn, the secondary packages are arranged on wooden structures (pallets) in order to result in a volume dimensioned according to the transportation container. In the centers of Internet sales operations are made the separations and re-packaging: the retail packaging will be coated by the dealer, usually consisting of: a) new cardboard box containing air or styrofoam bags to fit and protect from shocks; Or b) plastic or paper envelope internally coated with bubble-plastic with mechanical and climatic protection function. As a result, the volume of material destined to pack the product is exaggeratedly larger than the volume of the product, making the packaging an aspect of great impact by its immediate disposal. In addition, we could be infer that transportation to distributors and retailers is done by land. The large displacements resulting from the distribution of a product, produced in the south of the country, to different destination regions, imply significantly high atmospheric emissions. It would occur in lower scale if the plant were in the southeastern region of the country where there is a larger market.

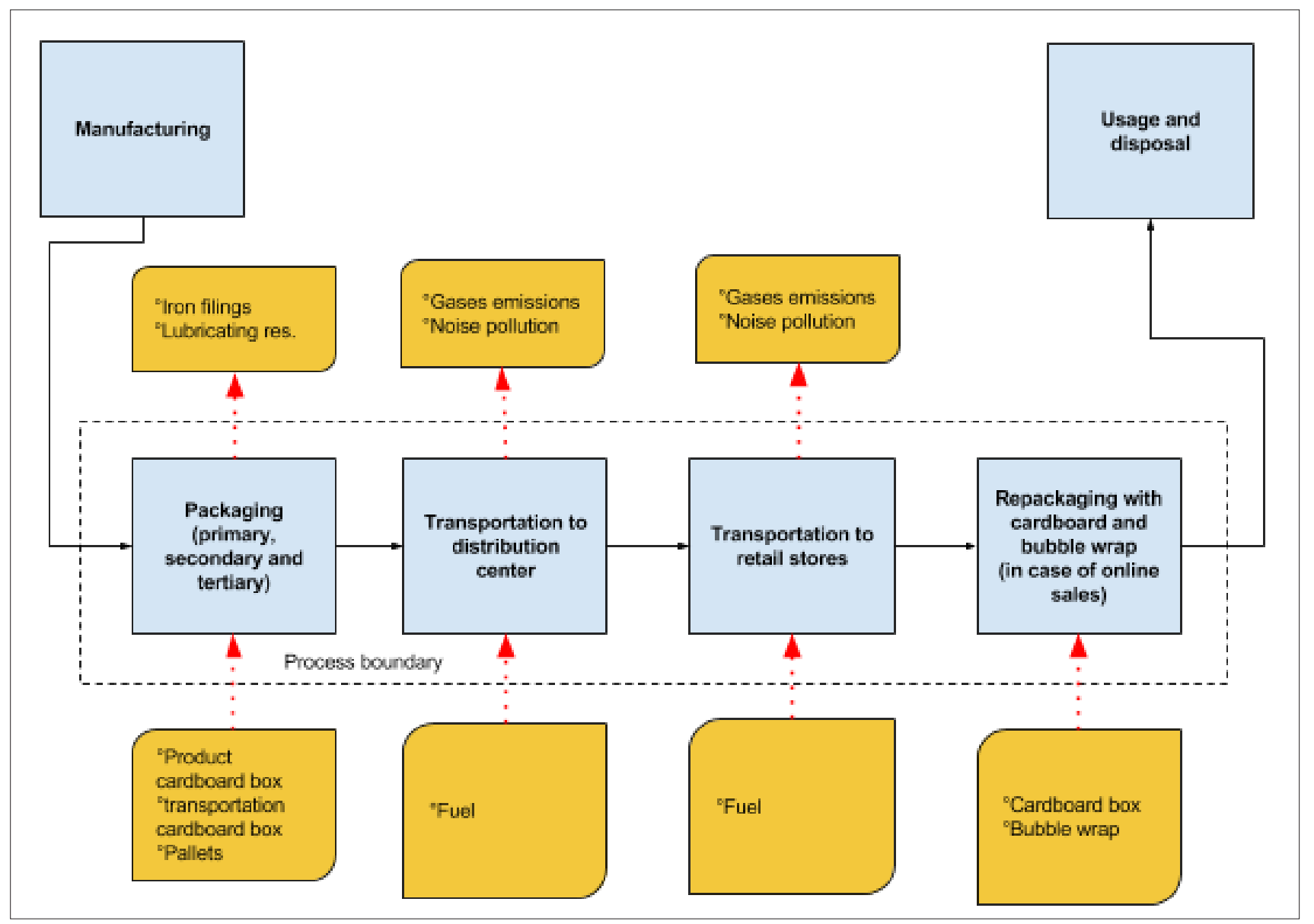

Figure 6. Flowchart of Packaging and Distribution process. 


\subsubsection{Process 4: Use and Disposal}

The final process, Use and Disposal, consists of two stages, as shown in the Figure 7.

The first use stage corresponds to the conveyance by the user, added of the needed complementary peripherals (external keyboard and mouse), disposal of packaging and use of the stand with the laptop to obtain its ergonomic postural benefits. It should be noted that the use of the extra peripherals is essential to obtain the expected postural benefits (SIMONEAU; MARKLIN, 2001; ASUNDI; JOHNSON; DENNERLEIN, 2011). Even though a considerable number of the interviewed subjects admits the use of the laptop stand without them, which may incur in damage to the wrists due to excessive flexion. This scenery highlights the social impact of the use, given the fact that this practice generates ergonomic risks. The combined packaging brought to the client's household is disposed with triage or not, depending on his habits. The lack of triage generate solid waste.

This stage lasts until the laptop stand is damaged, when it reaches the disposal stage in the end of its lifespan. The non-availability of spare parts by the manufacturer makes the maintenance or repair of the product unfeasible. Usually, the end-of-life is reached when the plastic parts loose adherence to the metal and the stand becomes unstable. Besides that, eventual loss of parts, mechanical shock and overload may also promote end-of-life. The product may be sent to recycling by recycling organizations that recycle both plastic and metal parts. Although the interviews with users show that the package as well as the product were disposed to the standard trash. The product was analysed under the premise of absence of substitution practice due to defects in workmanship and materials, but it should be noticed that, according to the manufacturer, the substitution rate in these cases is less than $0.5 \%$ of the total production.

\subsection{Product impact evaluation}

The evaluation of environmental aspects raised on the Inventory Analysis allows us to comprehend the environmental impacts caused by the product life cycle. It has been organized in Table 2, along with indications of which processes caused each impact.

\section{Innovation proposed}

A problem solving methodology was applied resulting on the assumption that the best solution would be to develop a new manufacturing method for the notebook which incorporates a built-in adjustable stand. Figure 8 shows the new concept proposed. It eliminates all the environmental

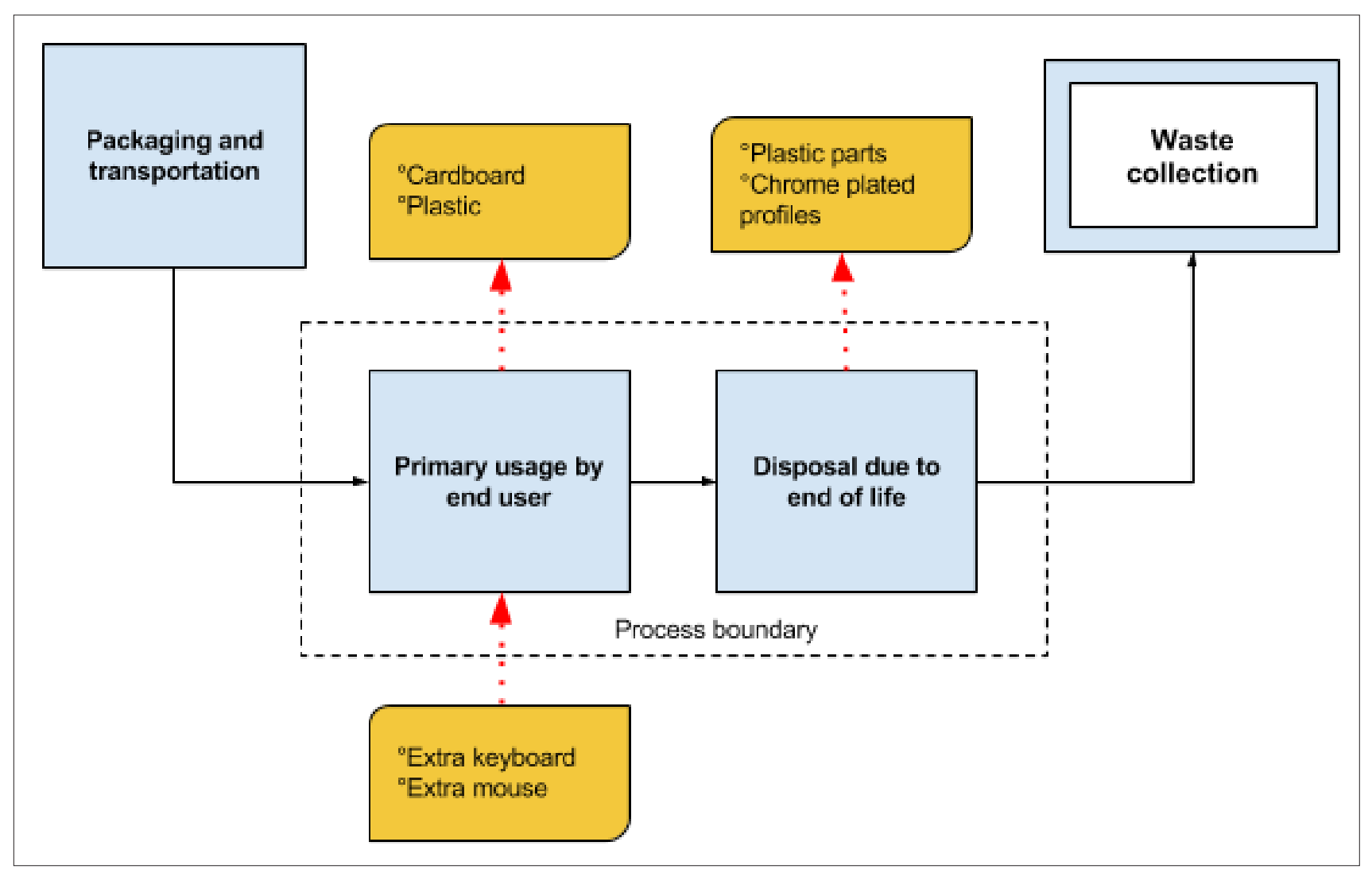

Figure 7. Flowchart of Use and Disposal process. 
Table 2. Evaluation of impacts of the UpTable adjustable laptop stand.

\begin{tabular}{|c|c|c|}
\hline Processes & Environmental Aspects & Environmental Impact \\
\hline \multirow{5}{*}{$\begin{array}{l}\text { Raw Material } \\
\text { Transportation }\end{array}$} & Fuel: use of fuel on transportation & Natural resources reserves reduction \\
\hline & Atmospheric emissions from the fuel burning & Air pollution \\
\hline & Generation of external noise from motor vehicles & Noise Pollution \\
\hline & Use of steel as raw material & Impacts of the steel production chain \\
\hline & Use of plastic as raw material & Impacts of the plastic production chain \\
\hline \multirow{4}{*}{ Manufacturing } & Atmospheric emissions from the fuel burning & Air pollution \\
\hline & Generation of external noise from motor vehicles & Noise Pollution \\
\hline & Use of steel as raw material & Impacts of the steel production chain \\
\hline & Use of plastic as raw material & Impacts of the plastic production chain \\
\hline \multirow{10}{*}{$\begin{array}{l}\text { Packaging and } \\
\text { Transportation }\end{array}$} & Cardboard box: primary packaging & Impacts of the paper production chain \\
\hline & Transportation cardboard box: product bales & Impacts of the paper production chain \\
\hline & Pallets: used for stacking products & Impacts of the wooden artifacts production chain \\
\hline & Iron fillings: solid waste & Environmental pollution: solid waste \\
\hline & Lubricant residue: liquid residue & Environmental pollution: liquid waste \\
\hline & Fuel: use of fuel on transportation & Natural resources reserves reduction \\
\hline & Generation of external noise from motor vehicles & Noise Pollution \\
\hline & Atmospheric emissions from the fuel burning & Air Pollution \\
\hline & $\begin{array}{l}\text { Cardboard box: use of extra packaging due to online } \\
\text { sale }\end{array}$ & Impacts of the paper production chain \\
\hline & $\begin{array}{l}\text { Bubble wrap: use of extra plastic wrap due to online } \\
\text { sale }\end{array}$ & Impacts of the plastic production chain \\
\hline \multirow{6}{*}{ Use and Disposal } & Extra keyboard & $\begin{array}{l}\text { Consumption of natural resources and other impacts of } \\
\text { the life cycle of the product keyboard }\end{array}$ \\
\hline & Extra mouse & $\begin{array}{l}\text { Consumption of natural resources and other impacts of } \\
\text { the life cycle of the product mouse }\end{array}$ \\
\hline & Cardboard: Descarte de caixas de papelão & Environmental pollution: solid waste \\
\hline & Plastic: disposal of plastic wrap & Environmental pollution: solid waste \\
\hline & Plastic parts: disposal of connections & Environmental pollution: solid waste \\
\hline & Chrome steel profiles: disposal of structure & Environmental pollution: solid toxic waste \\
\hline
\end{tabular}
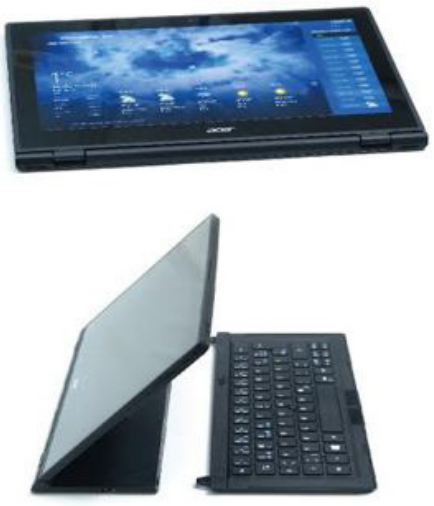

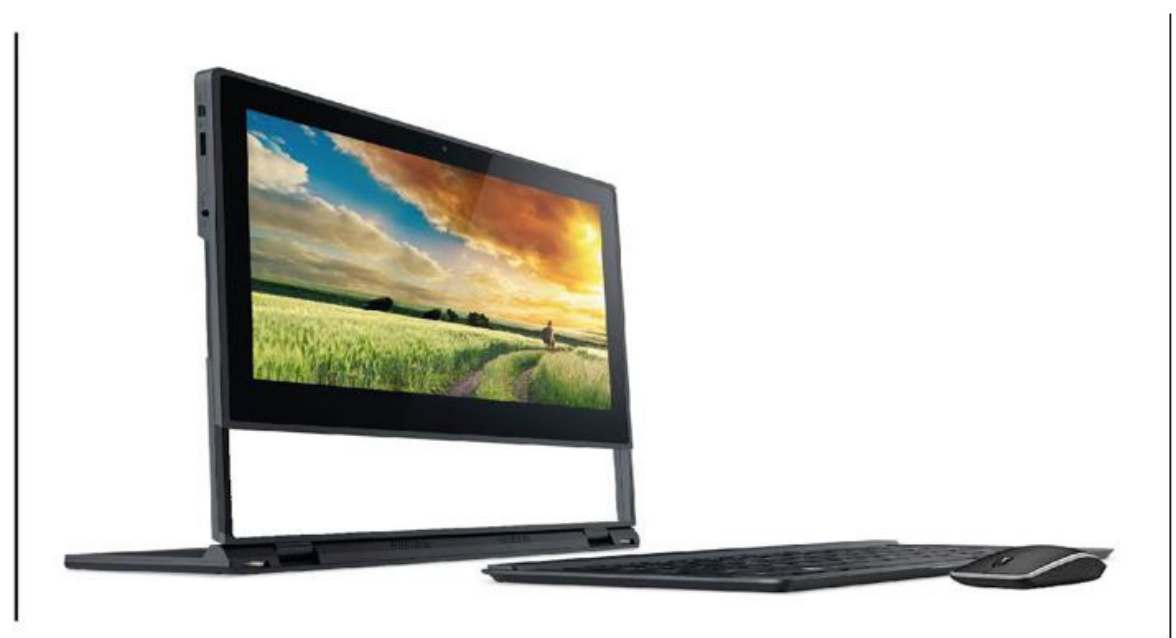

Figure 8. to the left, notebook Acer Aspire Switch 12, closed (above) and open with the keyboard detached (below). To the right, innovation proposal featuring screen height control.

impacts caused by the manufacturing of the laptop stand desk, as well as those regarding the mouse and keyboard manufacturing. Furthermore, it allows the whole logistics to be centered in a single product, preserving the ergonomic advantages without compromising the portability.

\section{Analysis of the results}

The innovative proposal was compared to the present manufacturing of the stand using ESW (FRAZÃO et al., 2003, COSTA; GOUVINHAS, 2003), presenting a graphic 
representation of the design strategies in a radar type chart orienting the improvement of the eco-efficiency profile of the product in its life cycle. The tool consists of eight comparative analysis rated 0 to 5 each.

\subsection{New concept development}

The UpTable laptop stand concept is not sufficient to solve the ergonomic issues by itself, given it requires the adoption of two other products. The elements become duplicated, once the laptop features an internal keyboard and touchpad. A dynamic balance between portability, sustainability and ergonomy became evident. This concept was rated 2, as it consists of a portable device that relies on other products resulting on a less portable and sustainable product system.

The developed concept incorporates the stand and eliminates peripherals redundancy (stand, mouse and keyboard). Such dematerialization of functions preserves portability by using modular detachable parts. The solution should result in a equipment that maintains the portability of the original laptop, while still working as a desktop workstation, and possibly without ergonomy loss, lesser environmental impacts and cost reduction. The innovative proposal was rated 5 for dematerializing the stand as it also eliminates the need for extra peripherals, while maintaining all the original features and advantages.

\subsection{Product component level}

The evaluation of the product components is divided in two topics.

\subsubsection{Selection of low impact materials}

The chromium added steel used in the UpTable laptop stand presents relatively low energetic content when compared to other metals and, despite the toxicity of the chrome plating, it is a recyclable material featuring ease of production. Therefore was rated 2 under this aspect. The innovative proposition assumes an environmental profile directed to the use of recycled materials and less aggressive processes in order to minimize the impact, which is the reason of being ranked 4 in this matter.

\subsubsection{Reduction of materials usage}

This topic regards of product dematerialization and service virtualization, in which the product can improve significantly in a global context. There is a great volume of packaging material in primary, secondary and tertiary packaging that increase the solid waste of each unit sold far beyond the product volume itself. Its weight is considerably low nevertheless, even when the peripherals are taken into account. In this matter the rate given was 3 . To the innovative proposition, the embedding of the laptop stand into the laptop results in great reduction of material. In the new situation the stand is strictly dimensioned to the size of the device, dismissing the need to fit to a wide range of different devices that caused it to be oversized to most of the users. The economy of raw material resulted in it rating 5 .

\subsection{Product structure level}

The evaluation of the structure level of the product consists of three evaluations as follow.

\subsubsection{Evaluation of production techniques}

Under this subject, the ideal emission of pollutants and input of materials to the production of the UpTable stand would be zero. Although, they do exist. Zero is to be considered the worst case, indicating the greatest expression of both items. As the product does not emit polluting gases, the grade 2 was conferred. To the innovative proposition, the manufacturing process would be kept similar, then, the same grade 2 was given.

\subsubsection{Optimization of distribution system}

The distribution system for the UpTable portable stand answers to multiple demands by distributors, wholesalers and retailers. The end user demands three different products to be delivered (stand, mouse and keyboard). Strategic manufacturing plant localization could move manufacturing closer to the major international and domestic distribution centers, also taking into consideration the materials original sites. Transportation could be optimised reducing fuel consumption and their emissions due to the reduction of distances, hence the plant is located in the south region and the product is mostly sold to the southeast of Brazil. The product folding and its reduced package dimensions already allow a neat modularization into secondary packaging and pallets. The amount reduction of cardboard paper alongside other materials used in packaging (plastic, wooden pallets, staple claps and glue) has been taken into consideration. Due to the positive and negative aspects it was rated 3 here.

The innovation proposition presents advantages beyond preserving the foretold ones, as it eliminates the laptop stand, keyboard and mouse as isolated products, given the fact those will be completely included in the distribution of the laptop itself. The innovation proposition gets a 5 rate under this subject.

\subsubsection{Reduction of impact during use}

During usage there is an ergonomic impact whether the user doesn't follow the manufacturer's recommendations. Another impact refers to the transportation in case of product substitution. But, once the former is for the user to decide and the latter is rare due to the substitution statistics 
around $0.6 \%$, the rate 4 has been assigned. The innovative proposition in the other hand has been rated 5 for embedding the stand as part of the laptop with mouse and keyboard detachable, and therefore extinguishing such impacts.

\subsection{Product system level}

\subsubsection{Optimization of initial lifetime}

Product presents high durability, being said to last longer than the notebook by the interviewed users. Because it's made of metallic material, it presents great resistance and its lifespan five years to the average user. Maintenance events nearly don't happen and the company would substitute the product due to defects during the warrantee period (1 year). Its modularity and timeless design together with its portability provide a good product-user relation, which is impaired by the demand of extra mouse and keyboard. The user's deception over the necessity of peripherals and the impact caused by not using them bring the rate of the product to 4 . Innovation shows improvement regarding the current portable stand desk problems, as it doesn't need peripherals. However, according to the material used in the new built-in laptop stand concept some durability loss may occur, once it becomes equal to the durability of the notebook, hence being rated 4 .

\subsubsection{Optimization of end-of-life system}

Reuse of product is possible as it is not limited to use with one laptop and does not need to be substituted along the substitution of the device. Besides, it allows alternatives of reutilization such as book and tablet stands. The remanufacturing of the product is viable, though it is not done, the user disposing it, case in which it may be collected to be recycled. The company does not offer to collect the product as a service, not even in case of substitution. The design is very easy to disassemble, with reduced amount of components, all of which simply fitted. Incineration is not used in the end-of-life. Therefore it was rated 4. Innovation proposition would permit easy detachment, making possible to recycle or remanufacture in the end of life span of the laptop, in case the manufacturer would collect it. So, it was rated 5 to the proposal.

\subsection{ESW chart}

A comparison of the ratings of present UpTable product and of the innovative proposition presented in a radar chart shows quantitatively in what extension the improvement of the proposition originated from the research delivers a more sustainable manufacturing engineering, as presented in Figure 9.

\section{EcoDesign Strategies Wheel}

- Asys UpTable $x$ Innovation Proposal

0-Product Concept

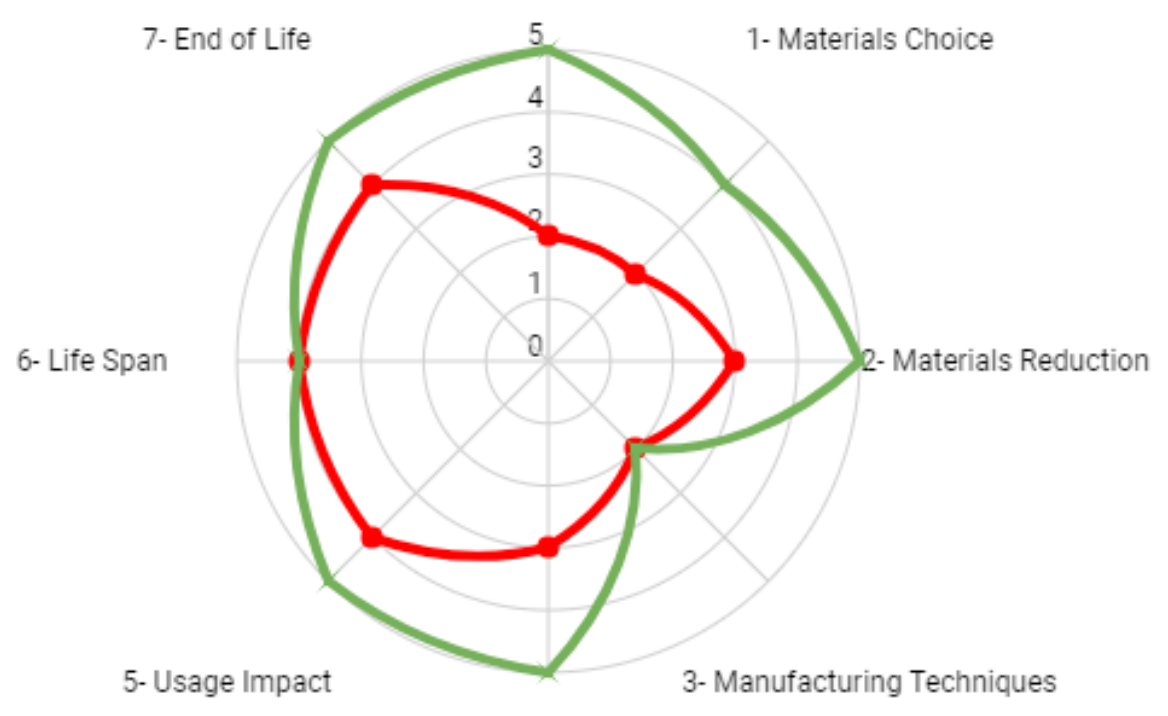

4- Distribution Reduction

Figure 9. Ecodesign Strategies Wheel (ESW). 


\section{Results and discussion}

The "UpTable adjustable laptop stand" is a prominent product in the universe of laptop stand for its awards as a quality product and for being the most popular in Brazil. Although it stands out for its reduced dimensions, its portability and its little variety of component materials, a deeper analysis reveals a high environmental impact of the product. The high impact is caused by various factors identified in the LCA, the most serious of which being: the use of toxic substances in the chromium plating process; no product recycling; risk of non sustainable use of the product due to use without necessary peripherals; excess of waste generated by the high amount of packaging required by each unity of the product; excessive atmospheric pollution and fuel consumption used by the whole transportation of materials and product delivery. The objective of the research was reached with the knowledge on the life cycle of the product and the configuration of an innovative proposition that presents a better manufacturing system.

\section{Conclusion}

The conclusion of this exploratory research demonstrate that the manufacturing choices are often determined in the product design stage, therefore it's of great importance to include the manufacturing engineer in this stage. It was noticed that in this case, a research initiated with focus on the manufacturing engineering of a product promoted as result changes in the design reinforcing the conclusion that manufacturing engineering and product concept are intimately connected.

In a situation of crescent adoption of laptops computers instead desktop models, the laptop stand brings environmental impact, as demonstrated. The ESW - Ecodesign Strategy Wheel highlighted some opportunities to design improvement and innovation of a popular UpTable portable laptop stand, providing manufacturing process that eliminates the peripherals redundancy and promotes economy of supplies with no prejudice to the portability that characterizes the device, reducing the environmental impact during the manufacturing process, utilization and discharge of the product. This paper approach is exploratory and require a posterior detailing and revision using the real data by manufacturer. But the paper main objective (the value of LCA and ESW as a contribution to product redesign) was demonstrated.

\section{Acknowledgements}

This research was sponsored by the FAPEMIG Foundation for Research Support of the State of Minas Gerais and the CNPq - Brazilian National Council for Scientific and Technological Development, an agency linked to the Ministry of Science and Tecnologia (MCT) of Brazil.

\section{References}

ASSOCIAÇÃO BRASILEIRA DE NORMAS TÉCNICAS ABNT. NBR ISO 14040:2009 Gestão Ambiental: Avaliação do Ciclo de Vida - Princípios e Estrutura. Rio de Janeiro, 2009a.

ASSOCIAÇÃO BRASILEIRA DE NORMAS TÉCNICAS ABNT. NBR ISO 14044:2009 Gestão Ambiental: Avaliação do Ciclo de Vida - Requisitos e Orientações. Rio de Janeiro, 2009b.

ALVES, L. L. et al. EcoDesign strategy wheel: appliance in a Santa-Cruz Sundial. Product, v. 14, p. 101-107, 2016.

ASUNDI, K.; JOHNSON, P. W.; DENNERLEIN, J. T. Does elevating and tilting the input device support surface affect typing force and postural exposures of the wrist? Work, v. 39, n. 2, p. 187-193, 2011.

ASUNDI, K. et al. Changes in posture through the use of simple inclines with notebook computers placed on a standard desk. Applied Ergonomics, 2012.

ASYS - PRODUCTS. Available from: $<$ http://www.asys.com. br/>. Access in: 19 Oct. 2016.

BAGNO, R. B.; LEIVA, T. L.; OLIVEIRA, L. G. H. Innovation management: lessons learned from innovation diagnostic tools. Product, v. 14, n. 1, p. 12-21, 2016.

COSTA, G. J.; GOUVINHAS, R. P. Ecodesign strategies and the product development process within Northeast SME Brazilian companies. In: INTERNATIONAL CONFERENCE ON ENGINEERING DESIGN - ICED 3, 14., 2003, Stockholm. Proceedings... Backwell: Design Society, 2003. p. 414-423.

FRANZ, L. A. S.; GUIMARÃES, L. G.; AREZES, P. M. F. M. A case study about laptop using and ergonomic implications in a Brazilian University. In: SIMPÓSIO DE ENGENHARIA DE PRODUÇÃO - SIMPEP, 18., 2011, Bauru. Anais... Bauru: UNESP, 2011. p. 1-10.

FRAZÃO, R; CONSTANÇA P; FERNANDES, R. Adoptar uma perspectiva de ciclo de vida. Caderno do INETI, $\mathrm{n}$. $10,2003$.

VAN HEMEL, C. G.; CRAMER, J. Barriers and stimuli for ecodesign in SMEs. Journal of Cleaner Production, v. 10, n. 5, p. 439-453, 2002.

VAN HEMEL, C. G. EcoDesign empirically explored; design for environment in Dutch small and medium-sized enterprises 1998. $271 \mathrm{f}$. Thesis - Technical University Delft, 1998.

LOJAS AMERICANAS. Suporte p/ notebook - Asys UpTable. Available from: <http://www.americanas.com.br/ produto/389404/suporte-p-notebook-asys-uptable $>$. Access in: 7 Sept 2016. 
NIGRI, E. M. et al. Assessing environmental impacts using a comparative LCA of industrial and artisanal production processes: 'Minas Cheese' case. Ciência e Tecnologia de Alimentos., v. 34, p. 522-531, 2014.

PEDROTTI, M; MISTURA, CM. Avaliação de aspectos e impactos ambientais do processo produtivo de uma metalúrgica de pequeno porte. Revista CIATEC - UPF, v .2, n. 2, p. 22-45, 2010.
PEREIRA, R. C. S.; NAVEIRO, R. M. Industrial design and innovation. Product, v. 5, n. 1, p. 5-15, 2007.

SILVA, C. S.; PEDROZO, M. F. M. Ecotoxicologia do cromo e seus compostos. Salvador: Centro de Recursos Ambientais, 2001. (Cadernos de Referência Ambiental, v. 5).

SIMONEAU, G. G.; MARKLIN, R. W. Effect of computer keyboard slope and height on wrist extension angle. Human Factors, v. 43, n. 2, p. 287-298, 2001. 